\title{
Tulane
}

Tulane Economics Working Paper Series

\section{Expanding Employment Discrimination Protections for \\ Individuals with Disabilities: \\ Evidence from California}

\author{
Patrick Button \\ Department of Economics \\ Tulane University \\ pbutton@tulane.edu \\ Working Paper 1601 \\ Original version: February 2016 \\ This version: October 2016
}

\begin{abstract}
Effective 2001, California passed the Prudence Kay Poppink Act which broadened California's disability employment discrimination law to cover individuals with less severe disabilities by lowering the burden of proof to establish a disability. I estimate how this act affected the labor market outcomes for individuals with disabilities using both difference-in-differences and differencein-differences-in-differences regression analyses and data from the Current Population Survey. The results suggest that the act significantly increased employment, with the effect persisting at least partially up to six years later.
\end{abstract}

Keywords: Disability, discrimination, labor employment law, Prudence Kay Poppink Act, Americans with Disabilities Act, Sutton Trilogy

JEL codes: J14, J71, J78, K31 


\title{
Expanding Employment Discrimination Protections for Individuals with Disabilities: Evidence from California
}

\author{
Patrick Button \\ Assistant Professor \\ Department of Economics \\ Tulane University
}

October 2016

\begin{abstract}
Effective 2001, California passed the Prudence Kay Poppink Act which broadened California's disability employment discrimination law to cover individuals with less severe disabilities by lowering the burden of proof to establish a disability. I estimate how this act affected the labor market outcomes for individuals with disabilities using both difference-in-differences and difference-in-differences-in-differences regression analyses and data from the Current Population Survey. The results suggest that the act significantly increased employment, with the effect persisting at least partially up to six years later.
\end{abstract}

JEL Codes: J14, J71, J78, K31

Keywords: disability, discrimination, labor employment law, Prudence Kay Poppink Act, Americans with Disabilities Act, Sutton Trilogy

\footnotetext{
${ }^{1} 6823$ St. Charles Avenue, Tilton Hall 206, New Orleans, LA 70118, pbutton@ @ulane.edu, patrickbutton.com. I am grateful to Marianne Bitler, David Neumark, and seminar participants at UC Irvine, Tulane University, and at the Southern Economic Association for helpful comments. I thank Adam Majewski for assistance with editing this manuscript for publication.
} 
Disability discrimination laws seek to boost the employment of individuals with disabilities by reducing discrimination and requiring employers to provide "reasonable accommodations" to individuals with disabilities, allowing them to overcome barriers that may prevent them from working. The most notable employment discrimination law in the United States is Title I of the Americans with Disabilities Act of 1990 (ADA), effective July 1992. In addition to forbidding discrimination in hiring, terminations, promotion, and wages on the basis of disability, Title I of the ADA requires employers to accommodate employees with disabilities by providing physical aids or some job restructuring, so long as this accommodation is reasonable given the nature of the job and size of the firm. The ADA applies to firms with at least 15 employees. The ADA provides three routes for an individual to be considered disabled:

“The term 'disability' means, with respect to an individual

(A) a physical or mental impairment that substantially limits one or more major life activities of such individual;

(B) a record of such an impairment; or

(C) being regarded as having such an impairment. (42 U.S. Code $§ 12102$ (1))”

However, proving that an impairment "substantially limits" a major life activity has proved difficult, particularly before the passage of the ADA Amendments Act of $2008^{2}$. Adding to this, coverage of the ADA further narrowed after the "Sutton Trilogy" of United States Supreme Court Cases $^{3}$ in June 1999, which excluded individuals with "mitigating measures" such as glasses,

\footnotetext{
${ }^{2}$ Defendants (employers) win the vast majority of cases because plaintiffs (workers) cannot establish that they qualify as disabled under the demanding "substantially limits" standard (Colker, 1999). Burgdorg (1997) (p. 536538) cites numerous cases stemming from Forrisi v. Bowen, 794 F.2d 931, 934 ( $4^{\text {th }}$ Cir. 1986) which interpreted the ADA to cover only the "truly disabled" and not those with more minor impairments.

${ }^{3}$ Sutton v. United Airlines (119 S. Ct. 2139 (1999)), Murphy v. United Parcel Service, Inc. (119 S. Ct. 2133 (1999)), and Albertson's Inc. v. Kirkingburg (119 S. Ct. 2162 (1999)).
} 
medication, or assistive devices, from being considered disabled if the mitigating measure(s) made their condition(s) no longer "substantially limit" a major life activity. Because the requirements to be considered disabled under the ADA was, and still is, demanding, a significant portion of individuals with less severe disabilities were not, and are still are not, covered by disability discrimination laws.

A significant change in disability discrimination law in California provides an opportunity to study the implications of expanding legal protection to additional persons with less severe disabilities. On September 30, 2000, California passed the Prudence Kay Poppink Act (PKP Act), which became effective January 1, 2001 (see Figure 1 for a timeline). This act made the following five changes to California's Fair Employment and Housing Act (FEHA) (Cal Gov Code $\$ 12900$ et seq.):

\section{[[Figure1 near here]]}

1. Changed the requirement that a condition "substantially limits" a major life activity, as in part (A) of the ADA definition of disability, to just "limits";

2. Ignored the "Sutton Trilogy" of U.S. Supreme Court cases;

3. Explicitly added "working" to the list of major life activities;

4. Explicitly considered several conditions such HIV/AIDS, hepatitis, epilepsy, seizure disorder, diabetes, clinical depression, bipolar disorder, multiple sclerosis, and heart disease to be disabilities without any requirement that they limit a major life activity; and 
5. Made it a punishable offense for an employer to fail to adequately participate in the interactive process with an employee or job applicant to determine effective reasonable accommodations.

The first four changes further broadened who was considered disabled in California ${ }^{4}$ and the last change sought to expand reasonable accommodations. Lawyers, employers, disability advocacy groups, and case law all saw the PKP Act as significant broadening of disability discrimination law in California ${ }^{5}$. I further discuss the changes resulting from the PKP Act in Online Appendix $1^{6}$.

I estimate the causal impacts of the PKP Act on employment of individuals with disabilities (those who report work limitations) aged 25 to 61. I use data from the Current Population Survey Annual Social and Economic Supplement (CPS ASEC), colloquially referred to as the "March CPS." I use the sample period of 1994 to 2007, which covers the period after the ADA became effective, but before the Great Recession and the ADA Amendments Act of 2008 (see the timeline in Figure 1).

I conduct two difference-in-differences (DD) regression analyses. The first compares Californians with disabilities, before and after the PKP Act, to those with disabilities in other states over the same time period ("DD-Disabled"). The second compares Californians with disabilities to Californians without disabilities over the same time period ("DD-CA"). I then combine both

\footnotetext{
${ }^{4}$ California's FEHA was already broader than the ADA in one dimension: FEHA applies to firms with at least five employees, while the ADA applies to firms with at least 15 employees.

${ }^{5}$ For lawyers see http://www.larryminsky.com/article1.aspx, http://kuchlforsupervisor.com/sheila-kuchls-10-billsthat-changed-california/, http://www.sohnenandkelly.com/2011/12/18/the-rights-of-applicants-under-fairemployment-law-caaaments/. For employers see http://www.puenteconsulting.com/PDFs/Business\%20Law\%20Practioner_Disability\%20Article.pdf (all accessed May 11, 2015). For case law see, most notably, Colmenares v. Braemer Country Club, Inc., 63 P.3d 220, 223 (Cal. 2003), but also Diffey v. Riverside County Sheriff's Dept., 101 Cal. Rptr. 2d 353 (2000).

${ }^{6}$ All online appendices are available at http://www.[MyDomain].com/research
} 
control groups (individuals with disabilities in other states, Californians without disabilities) to estimate a difference-in-difference-in-differences (DDD). This DDD allows me to control for average differences in those with and without disabilities in each state, economic conditions in states over time that affect those with and without disabilities equally, and national trends over time for those with disabilities, relative to those without disabilities.

I find that the PKP Act led to a substantial increase in employment for individuals with disabilities. My preferred estimate is a 3.8 percentage point increase in the probability of being employed, on average, over six years after the PKP Act was in effect. This effect seems to weaken somewhat after the first three years, but most evidence suggests that the effect was not short-term. This employment increase is large relative to the employment-to-population ratio for individuals with disabilities in California before the PKP Act came into force (24.5\%). My results suggest that broader disability discrimination laws may improve labor market attachment for individuals with disabilities.

\section{Related Research}

\section{Disability Discrimination Law}

The effect on employment of such an expansion of disability discrimination law to those with less severe disabilities is unclear based both on theory and on the empirical literature. Economic theory provides ambiguous predictions as to the effects of employment discrimination laws. Economic theory suggests that these laws should reduce job terminations because terminating an employee, whether there is discriminatory intent or not, opens employers to the risk of legal action (Acemoglu and Angrist, 2001). Tenure at jobs could also increase because the "reasonable accommodations" that the employer provides could increase job satisfaction, help manage health conditions, or increase productivity. 
While there is strong evidence that disability discrimination laws reduce terminations, there is ambiguous evidence for how they affect hiring. Economic theory suggests that the increased cost or risk from terminating a protected worker makes hiring a protected worker more costly (Bloch, 1994). Added to this are the costs of reasonable accommodation for disability discrimination laws (or the costs of possibly being sued for not providing it), which further increases hiring costs (Acemoglu and Angrist, 2001).

On the other hand, employment discrimination laws forbid discrimination in hiring, which could, of course, increase hiring. However, there is likely limited ability for the law to protect against hiring discrimination as it is difficult to prove or detect, and thus there is less enforcement. In hiring discrimination cases it is also more difficult to identify a class of affected workers, and economic damages are smaller than in termination cases. These circumstances result in fewer negative consequences to employers that wish to discriminate at the hiring stage, which suggests negative hiring effects (Bloch, 1994). Even absent the ability of these laws to reduce hiring discrimination, hiring could increase because the creation of expansion of disability discrimination protections motivates employers to project a good corporate image, as there may be more awareness of disability-related issues ${ }^{7}$.

The empirical literature also has ambiguous predictions for if disability discrimination laws increase or decrease employment. The first studies analyzing the ADA find that it was associated with a decline in employment for individuals with disabilities after the ADA, relative to individuals without disabilities (DeLeire 2000, Acemoglu and Angrist 2001). Kruse and Schur (2003), Hotchkiss (2004), Houtenville and Burkhauser (2004), and Jolls and Prescott (2004) disputed these studies for different reasons. Kruse and Schur (2003) find that the effects of the ADA varied

\footnotetext{
${ }^{7}$ I thank an anonymous referee for raising this point.
} 
depending on how disability is defined. They replicate the negative estimated effects of the ADA found in DeLeire (2000) and Acemoglu and Angrist (2001) using the "work-limited" definition of disability, where individuals are deemed disabled if they or their proxy answer "yes" to a question asking if they have a condition that limits the amount of type of work that they can do. However, Kruse and Schur (2003) find a positive effect of the ADA if disability is defined as having a limitation to an "activity of daily life," which is more in line with the definition of disability under the ADA. Hotchkiss (2004) shows that the negative estimated effect of the ADA in previous studies was due to a reclassification of individuals without disabilities who were out of the labor force as "disabled." Houtenville and Burkhauser (2004) argue that the negative estimates were due to a decreasing trend in the labor force participation rate of individuals with disabilities that started in the 1980s and arose because SSDI and SSI programs became more accessible, a trend also noted by Bound and Waidmann (2002). Houtenville and Burkhauser (2004) also find no evidence of a negative effect of the ADA if they use only those who report a work-limitation two periods in a row, rather than everyone who reports a work-limitation. In fact, they find some positive effects of the ADA using this two-period measure. Jolls and Prescott (2004) add an important nuance to the literature, finding that the negative effects of the ADA estimated in Acemoglu and Angrist (2001) and DeLeire (2000) were temporary and only occurred in states without an existing disability discrimination law that required reasonable accommodations. While the literature covering the effect of the ADA is quite strong, there is no obvious consensus on if disability discrimination laws have a positive, negative, or no effect on employment.

There are two studies on discrimination laws other than the ADA on the employment of individuals with disabilities. Beegle and Stock (2003) examine the effect of state disability discrimination laws adopted before the ADA. They generally find no effect of these laws on 
employment after controlling for pre-existing differential employment trends for individuals with disabilities. In contrast to Jolls and Prescott (2004), it appears that these effects are not mediated by if the state law required reasonable accommodations. Bell and Heitmueller (2009) analyze the United Kingdom's Disability Discrimination Act, passed in 1995, which shares characteristics of the $\mathrm{ADA}$, and find negative effects on employment, at least in the short-term.

While this research is informative, these studies do not speak much to an expansion of legal protections to those with less severe disabilities. This is a group for which the effects of legal protections likely differs, for two reasons. First, this group has stronger labor force attachment, so the expanded law could have even stronger effects, in either direction. Second, if, as in Jolls and Prescott (2004), there are only effects of disability discrimination laws that mandate reasonable accommodations, then, compared to the effects of the ADA, the effect of the PKP Act could be more muted because individuals with less severe disabilities need fewer accommodations (this is discussed in-depth in Online Appendix 1). Both these mechanisms make it less clear what the effects of an expansion of disability discrimination protections, such as the PKP Act, would be.

There is one recent study that does focus on an expansion of protections to those with less severe disabilities. Thompkins (2015) provides a first look at the effects of changes in the federal definition of disability (U.S. Supreme Court cases such as the Sutton Trilogy, the ADA Amendments Act of 2008) on the employment of individual with disabilities, using the "worklimited" measure. Thompkins (2015) seems to find few effects of federal changes on employment, although her evidence is difficult to interpret ${ }^{8}$.

\footnotetext{
${ }^{8}$ First, it is difficult to determine the effects of some U.S. Supreme Court decisions separately from each other, because they occur in close succession. Second, Thompkins (2015) does not explore the pre-existing trends issue sufficiently. Third, Thompkins (2015) estimates many of the effects separately based on the pre-existing state laws, using the law variables in Jolls and Prescott (2004). But many of these state laws have changed since then, and it is unclear how these state laws mediate the effect of federal changes, especially when concepts like the definition of disability under state laws are closely tied to the federal case law.
} 


\section{Other Discrimination Laws}

The effect of discrimination laws on the employment of other protected groups also provides some insight on the likely effects of the PKP Act. The theoretical effects are similar, although the hiring disincentive is smaller for other laws since they do not mandate reasonable accommodations. The empirical literature generally shows positive effects of discrimination protections on the employment of Blacks and older workers, but there is far from agreement. The literature on sex is much less developed and reaches mixed conclusions.

There are several studies of age discrimination with most showing positive effects. Adams (2004) and Neumark and Stock (1999) find that state and federal age discrimination laws increased employment of protected older workers. Neumark and Song (2013) find increased hiring of older workers "caught" by the increase in Social Security's full retirement age in states with stronger age discrimination laws. However, Lahey (2008) finds decreased hiring rates associated with the enforcement of the Age Discrimination in Employment Act (ADEA) of 1968 in states where it was easier to file a claim, although Neumark (2009) and Neumark and Button (2014) dispute the interpretation of these results. Neumark and Button (2014) find more mixed evidence suggesting that the effect of age discrimination laws may vary over the business cycle.

The bulk of the literature on sex and race is discussed in Neumark and Stock (2006) and Donohue (2007). Neumark and Stock (2006) and Donohue and Heckman (1991) show improvements in the employment of Blacks relative to Whites (and also women relative to men in Neumark and Stock (2006)) after Title VII of the Civil Rights Act of 1964. However, both suggest that it is difficult to prove that this is a causal effect because there were even stronger improvements generated in earlier periods by more secular forces. Donohue (2007) further argues that the federal law did, in fact, increase employment of Blacks. On the other hand, Neumark and Stock (2006) do 
not find employment increases for Blacks after state race discrimination laws passed, but. Neumark and Stock (2006) further find that state laws forbidding wage discrimination based on sex led to a decrease in employment for women. Most other studies of the effect of sex discrimination laws focus on wages and earnings, as do the recent literature on the effect of discrimination laws protecting gays and lesbians (e.g., Martell 2013).

\section{Data}

I use data from the Current Population Survey's Annual Social and Economic Supplement (CPS ASEC), via IPUMS-CPS (Flood et al., 2015). This data is often referred to as the "March CPS" since this supplement occurs primarily as an add-on to the CPS's monthly survey in March. The primary benefit of this data is a large sample size: about 6,616 individuals with disabilities and 78,883 individuals without disabilities per year in my sample, which allows more accurate estimates of labor market outcomes at the state level, which is crucial to this analysis.

The CPS ASEC, unlike the basic monthly CPS, asks the question that establishes if an individual has a work-limiting disability: "Does [insert name] have a physical, mental, or other health condition that limits the kind or amount of work [insert name] can do at a job or business?" I deem individuals to be disabled if they or their proxy answer "yes" to this question. I discuss this disability measure further later.

In creating my sample, I restrict my time period to 1994 to 2007. I start my sample in 1994 for two reasons. First, I want to avoid the possible short-term effects of the ADA that varied by state due to states that had different pre-existing discrimination laws (Jolls and Prescott, 2004). Second, I want to avoid changes in the CPS interview procedure, where the CPS moved to a computer assisted (CATI) design from 1993 to 1994, which may have affected the measurement of people with work-limiting disabilities (Kruse and Schur, 2003). The 2007 cut-off is for two 
reasons. First, I wish to exclude the Great Recession period (December 2007 to June 2009) to avoid picking up its adverse impacts ${ }^{9}$. Second, the ADA Amendments Act of 2008 (ADAAA) became effective on January 1, 2009, and it is not the focus of this study. See Figure 1 for a timeline that presents my sample period and major events before, during, and after this time. My other sample restriction is to restrict the sample to ages 25 to 61 to focus on individuals with more labor market attachment ${ }^{10}$. I include both women and men in my sample ${ }^{11}$.

\section{Sample Demographics}

Table 1 present means of the demographic variables (which are also regression controls) in the sample. I show the means by disability status, geography (California or outside California), and time period (before the PKP Act, 1994 to 2000, and after, 2001 to 2007). There are eight means to mirror the difference-in-differences (DD) and the difference-in-difference-in-difference (DDD) methodologies presented later. All means incorporate population weights to create populationrepresentative statistics. Individuals with disabilities are on average older, about five years, reflecting the increasing onset of disability with age, are more likely to be Black, are less likely to be Hispanic, are less educated, and are less likely to be married. Californians are slightly younger, are more likely to be Asian or Hawaiian/Pacific Islander or Hispanic, and less likely to be Black. Californians have a lower likelihood of reporting that they are work-limited: $7.5 \%$ in the pre-period versus $8.3 \%$ outside of California. I present these rates of disability over time in Figure 2.

\section{[[Table 1 near here]]}

\footnotetext{
${ }^{9}$ My time period does include the 2001 recession (March 2001 to November 2001), which occurs in the year the PKP Act first becomes active. Daly and Furlong (2002) profile the recession in the U.S. and California and show that job losses were slightly higher nationally than in California, but the trends were similar, especially in the later recessions, this recession was relatively short (eight months) and mild (Kliesen, 2003).

${ }^{10}$ I remove those younger than 25 as these individuals are far more likely to be in school. I remove those 62 and older because they may become eligible for Social Security Retirement Benefits.

${ }^{11}$ My employment results are similar for women and men separately. These results are available in Online Appendix 4. For men, employment increases come from net movements from unemployed to employed, while for women they come from not in the labor force to employed.
} 


\section{Labor Market Outcomes}

While I study employment, unemployment, and labor force participation, I focus on employment as it is the best of the three as a gauge of the success of individuals with disabilities in the labor market ${ }^{12}$. However, there are two different employment variables that are available: an indicator variable for being employed at the time of the survey and the weeks worked last calendar year. The employment indicator is preferable because the employment status question is asked in reference to the current period, as is the question about disability, while the weeks worked question refers to the previous calendar year. There is a non-trivial proportion of individuals in the sample who indicated that they were disabled at the time of the interview, and reported their weeks worked last calendar year, but may not have answered that they were disabled last year ${ }^{13}$. Also, the employment indicator has the advantage that it can be compared to indicator variables for being unemployed or in the labor force to understand net movements among these three categories. Weeks worked last calendar year does have the advantage, though, of capturing variation within the calendar year in employment, while the employment indicator only captures employment at a point in time. While I present results using the employment indicator, I find similar results using weeks worked last calendar year (see Online Appendix 4).

Table 2 presents summary statistics of labor market outcomes and state-level labor market and policy controls (state unemployment rate, extra weeks of unemployment insurance available) that are used in the regressions. Only about a quarter of individuals with disabilities are employed,

\footnotetext{
${ }^{12}$ While the unemployment rate is often used as a barometer of the labor market, Burkhauser, Houtenville and Wittenburg (2001)[p. 3] argue that it is better to look at employment rates for individuals with disabilities because unemployment rates capture only a subset of individuals with disabilities who are more attached to the labor market. ${ }^{13}$ Burkhauser, Houtenville, and Wittenburg (2001) compare the work-limitations measure in the CPS to a twoperiod measure where individuals report work-limitations in two consecutive years. Burkhauser, Houtenville and Wittenburg (2001) find that the incidence of disability in the CPS in 1996 using the one period (standard) disability measure is about $8 \%$ while for the two-period measure it is about 5\% (see Exhibit 3). Thus far fewer individuals report being disabled two years in a row, so there is a non-trivial probability that an individual reporting being disabled at the time of the survey was not disabled during the last calendar year.
} 
relative to about four-fifths of individuals without disabilities. Most of this employment gap is due to individuals with disabilities not being in the labor force. The proportion unemployed is slightly lower for individuals with disabilities than for individuals without disabilities, likely due to lower labor market attachment. Also presented in Table 2 are two additional control variables: the extra available weeks of Unemployment Insurance (UI) and the state unemployment rate.

\section{[[Table 2 near here]]}

\section{Definition of Disability}

As discussed by Burkhauser et al. (2002), there is no single definition of disability. This "work-limited" measure of disability is the most commonly used in the literature (see, e.g., Acemoglu and Angrist 2000; DeLeire 2000; Beegle and Stock 2003; Houtenville and Burkhauser 2004; Hotchkiss 2004; Jolls and Prescott 2004; Thompkins 2015). Different measures of disability capture different (but overlapping) groups. The ideal disability measure to quantify the impacts of the PKP Act would be to use a disability measure that closely matches the definition of disability in California's FEHA after the PKP Act, but not before. Thus, those covered by the measure are not covered by FEHA before the PKP Act, but they are after. This would allow for the most accurate estimate of the effect of the PKP Act on the affected population. In this case, as is the case with other studies in this literature, the measure of disability does not perfectly overlap with the treatment group.

The question is, then, how well does the work-limited measure correspond to the definition of disability in FEHA after the PKP Act? For one of the changes in the PKP Act, there is a good match. One of the changes was to deem “working” a major life activity under California's FEHA ${ }^{14}$,

\footnotetext{
14 “...Further, under the law of this state, 'working' is a major life activity, regardless of whether the actual or perceived working limitation implicates a particular employment or a class or broad range of employments." (Cal. Gov. $\$ 12926.1(\mathrm{c}))$
} 
but this was not deemed a major life activity in ADA case law. For individuals who report being work-limited to prove that they are disabled under the ADA, they must prove that their reported work limitation substantially limits a major life activity or limits them from working in a class of jobs or a broader range of jobs (Long, 2008). It is not enough for them to argue that their condition limits them just in a particular job. Under FEHA after the PKP Act, individuals can use "working" as a major life activity and in doing so it is enough to show a limitation to working in a particular job $^{15}$. Thus, those who report being work-limited are much more likely to be deemed disabled under FEHA after the PKP Act than under the ADA if the reported work-limitation is in reference to a particular job (a current or a recent job).

On the other hand, the work-limited measure does not explicitly align with other parts of the disability definition in FEHA after the PKP Act. The most notable change in the definition in FEHA after the PKP Act was the requirement that the impairment "limits" rather than "substantially limits" a major life activity. This work-limited measure does not explicitly include those who are only limited but not substantially limited. It includes many individuals who are both "substantially limited" and just "limited" in major life activities. So the work-limited measure is unable to isolate just those who became "treated": those "limited" by not "substantially limited." Similarly, the work-limited measure also does not isolate just those diagnosed with a condition that is explicitly covered under FEHA after the PKP Act. It also does not isolate those who use mitigating measures but that don't meet the "substantially limits" requirement when using mitigating measures. Even if more detailed survey data, such as the SIPP, were used to construct

\footnotetext{
15 There have been several cases where plaintiffs could only establish that their condition limited the major life activity of working only in their particular job. See, e.g., Sutton v. United Airlines (119 S. Ct. 2139 (1999)); Diffey v. Riverside County Sheriff's Dept., 101 Cal. Rptr. 2d 353 (2000); Toyota Mfg., Ky., inc. v. Williams (00-1089) 534 U.S. 184 (2002) 224 F.3d 840. Also, see Online Appendix 1 for additional discussion.
} 
an alternative measure of disability, it would be difficult to construct a disability measure that explicitly captured these changes.

However, researchers have shown that the work-limited measure of disability is highly correlated with other more objective assessments of health and with clinical measures of disability (Burkhauser, Houtenville and Wittenburg, 2001). More importantly, Burkhauser et al. (2002) show that while the work-limited measure does not capture everyone with disabilities, trends in the prevalence of work-limitations and of employment for the work-limited match these same trends using limitations measures. Thus, Burkhauser et al. (2002) conclude that the work-limited measure is appropriate for monitoring trends in outcomes of those with disabilities, which provides support for its use in this study.

\section{Possible Endogeneity of the Work-Limited Measure of Disability}

However, many criticize the work-limited measure of disability because individuals may report their work-limitation conditional on their employment status (Bound, 1991; Kerkhofs and Lindeboom 1995; Bound and Burkhauser 1999; Kruse and Schur 2003; Oguzoglu, 2012), conditional on characteristics of their job, such as employer-provided accommodations (Kruse and Schur 2016), or conditional on employment discrimination protections (Kapteyn, Smith, and van Soest, 2011). Endogeneity with employment is more likely with the work-limited measure compared to other measures (e.g., functional limitations) since it is asked with reference to employment. Several researchers demonstrated this endogeneity. Burkhauser et al. (2002) shows that for individuals with a reported impairment (e.g., blind in both eyes), those that report being work-limited are more likely to be employed than those who are not. This suggests that individuals who have an impairment but are sufficiently integrated into the workforce do not report a work 
limitation. Kreider (1999), Kreider and Pepper (2007), and Kapteyn, Smith, and van Soest (2011) find that those who are not working appear to systematically over-report that they are work-limited.

Thus, changes in the composition of who reports being work-limited could occur if the PKP Act affects employment or the receipt of workplace accommodations. If the PKP Act increases employment or accommodations for individuals with disabilities, then some of the newly employed or accommodated individuals with disabilities may no longer report that they are worklimited. Thus, some of the newly or currently employed individuals with disabilities are not counted as having a disability, negatively biasing the estimated employment effect. Similarly, if the PKP Act reduces employment, then there is increased movement of individuals with disabilities, who are employed but do not report being work-limited, to being not employed but reporting being work-limited. Either way, the bias is negative ${ }^{16}$.

To investigate if there was a change in reporting being work-limited after the PKP Act, I first present Figure 2, which presents the proportion of the sample by year that reports being worklimited for California and other states. This figure presents probabilities based on raw annual averages in addition to regression-adjusted annual average probabilities of reporting a work limitation. The regression-adjusted probabilities come from the DD logit regression model below:

$$
\text { Disabledist }_{1}=\alpha_{W-L} \text { PKPAct }_{s t}+\text { Controls }_{s t} \lambda+T_{s t} \rho+X_{i} \beta+\theta_{s}+\gamma_{t}+\epsilon_{i s t}
$$

Disabledist is an indicator variable if individual $i$ in state $s$ and year $t$ reports being worklimited. PKPActst is an indicator variable for living in California in 2001 or later. The coefficient of interest, $\alpha_{W-L}$ captures the change in probability that individuals in California report being worklimited after the PKP Act, relative to individuals in other states. captures the change in probability

\footnotetext{
${ }^{16}$ There is a remote possibility of positive bias. As mentioned by a referee, the PKP Act could have removed some of the stigmas of having a disability, leading more individuals in California to report being work-limited. If this occurred, and it occurred more for the employed compared to the non-employed, then this would explain some of my positive estimates. While I cannot rule this out, I consider it very unlikely.
} 
that individuals in California report being work-limited after the PKP Act, relative to individuals in other states. $\gamma_{t}$ are year fixed effects which capture national-level changes, such as declining employment of individuals with disabilities over time or changes in Social Security Disability Insurance. $\theta_{s}$ are state fixed effects which capture time-invariant state characteristics, such as differences in state laws that are consistent during the sample (see, e.g., Neumark, Song and Button 2016). $X_{i}$ is a set of individual covariates, more specifically indicator variables for each possible gender, race, Hispanic ancestry, marital status, age in years, and reported level of education.

\section{[[Figure 2 near here]]}

$T_{s t}$ are state-specific linear time trends, which are included in one set of regressions. As shown in Mora and Reggio (2013), DD estimates often change significantly in magnitude and statistical significance depending on to what extent group-specific time trends are included in the regression. Regressions with group-specific linear time trends are more appealing because they rely on a weaker assumption ("Parallel Growth", to use the language in Mora and Reggio 2013) than the model without these trends (which assume "Parallel Paths"). If the "Parallel Paths" assumption does not hold, then estimates are biased when group-specific linear time trends are excluded $^{17}$.

Controls st contains four sets of controls for state-level policies or economic conditions that may have affected self-reported disability status:

\footnotetext{
${ }^{17}$ While the inclusions of these group-specific time trends may reduce bias, they could also attenuate estimates. Meer and West (2016) shows that if the treatment effect occurs as a change in the growth rate of the independent variable (i.e. growth in the employment rate) instead of or in addition to a change in the level of an independent variable (i.e. employment rate increase), then including group-specific time trends will attenuate estimates by absorbing some of the growth effect. As the results show later, these results are unaffected by the inclusion of these trends. The later labor market outcome estimates become even stronger when group-specific time trends are included, suggesting that attenuation likely isn't occurring (and if it is, the true estimates are actually larger). Thus, Meer and West (2016)'s criticism of group-specific time trends is much less of a concern here.
} 
1. a set of four indicator variables to control for minor changes in disability discrimination laws in Maine, Rhode Island, and Washington (see Online Appendix 2 for more details);

2. a set of five indicator variables to control for job creation hiring credits at the state level that specifically targeted individuals with disabilities (from Neumark and Grijalva 2013) ${ }^{18}$;

3. the number of additional weeks of unemployment insurance (UI) available by state and year (from Farber and Valletta 2015) ${ }^{19}$; and,

4. the state unemployment rate ${ }^{20}$.

While the series are nois $y^{21}$ for California in Figure 2, the series for California and other states seem to track, as both states experienced a decrease in reporting being work-limited over time. The figure doesn't show any clear change that occurred only in California after the PKP Act.

Table 3 presents estimates from this regression using both a logit and a linear probability model. I present confidence intervals estimated following Conley and Taber (2011) in addition to those based on state-clustered standard errors. Due to the nature of the procedure used to construct Conley-Taber confidence intervals, it is not possible in my application to test for statistical significance at the 0.01 level, so I can only test at the 0.10 and 0.05 levels $^{22}$. Online Appendix 3

\footnotetext{
${ }^{18}$ Maryland's "Disability Employment Tax Credit", available from 1997 onward, New Jersey's "Income Tax Credit for Employment of Certain Handicapped Persons" from 2006 onward, New York's "Credit for Employment of Persons with Disabilities", Tennessee's "Credit for Hiring Disabled Persons" from 2006 onward, and Utah's "Hiring Persons with Disabilities (Targeted Jobs Tax Credit)" from 1995 onward. See Neumark and Grijalva (2013) for more details.

${ }^{19}$ This is the number of extra weeks of UI that were available from 2002 to 2007 due to the federal Extended Benefits program and another temporary program that was available in the early 2000s (Farber and Valletta, 2015). This is used as a control variable in the regressions since the extra weeks available varied by state over time. Extra weeks of UI were available for all states for most of 2002, all of 2003, and about half of 2004, but only for two states in 2005 and one state in 2006.

${ }^{20}$ This is from the Bureau of Labor Statistics. The specific series is LAUSTxx0000000000003, where "xx" is replaced with each state's Federal Information Processing Standard (FIPS) code.

${ }^{21}$ Estimates of the population of those with disabilities are particularly variable. See http://www.bls.gov/cps/cpsdisability_faq.htm (accessed April 8, 2015) for a discussion.

${ }^{22}$ A $99 \%$ confidence interval requires as at least 200 groups. I have only 51 groups in the DD (50 states plus DC), and 102 groups in the DDD (state-by-disabled, so $51 \times 2$ ).
} 
discusses further how I construct Conley-Taber confidence intervals and why they are likely to be more accurate.

\section{[[Table 3 near here]]}

The regression estimate of $\alpha w-L$ under a linear probability model is 0.004 without specific linear time trends, and -0.004 with them, but neither is statistically significant. Results are similar with a logit model. Thus there is insufficient evidence to conclude that there were changes in reporting being work-limited that coincided with the PKP Act. This suggests that it is unlikely that my estimates are negatively biased due to self-reported disability status being endogenous to the effects of the PKP Act.

\section{Methods}

I use three related panel regression methodologies. The first is a difference-in-differences (DD) using a sample of only those with disabilities ("DD-Disabled"). This DD compares individuals with disabilities in California before and after the PKP Act passed in 2002 to individuals with disabilities in other states over the same time period. The second is a DD using a sample of Californians only, comparing Californians with disabilities to Californians without disabilities ("DD-CA"). The third is a difference-in-differences (DDD), which incorporates both control groups ${ }^{23}$.

\section{Difference-in-Differences: Sample with Disabilities (DD-Disabled)}

The regression model for the DD-Disabled is:

$$
Y_{i s t}=\alpha_{D D-D i s} P K P A c t_{s t}+X_{i} \beta_{D D-D i s}+\text { Controls }_{s t} \lambda_{D D-D i s}+T_{s t} \rho+\theta_{s}+\gamma_{t}+\epsilon_{i s t}
$$

\footnotetext{
${ }^{23}$ I choose panel regression over an Abadie, Diamond and Hainmueller (2010) synthetic control case study because the Abadie, Diamond and Hainmueller (2010) synthetic control only allows for the DD-Disabled but not the DD-CA or the DDD.
} 
which is very similar to Equation 1. PKPAct st is again an indicator variable equal to one for 2001 or later and living in California. The coefficient of interest is $\alpha_{D D-D i s}$, which captures the effect of the PKP Act on the outcome variable, $Y_{i s t}$, for individuals with disabilities. The primary outcomes, $Y_{i s t}$, that I investigate are employment, unemployment, and labor force participation, all of which are binary variables. For outcome variables that are binary, I run both linear probability and logit models, which yield similar results (logit results for employment are presented in Online Appendix 4). I present both Conley-Taber confidence intervals and confidence intervals from clustering on state.

I estimate the regression above both with and without state-specific linear time trends $\left(T_{s t}\right)$. To further investigate if these trends are appropriate, and thus if the parallel path assumption holds, I follow Reber (2005) and Mora and Reggio (2013) and estimate the treatment effect separately for each year. The validity of the parallel paths assumption can be investigated by observing the trend in the annual treatment effect estimates in the pre-treatment period. In addition it is possible to see the treatment effect over time by inspecting the treatment effect estimates by year in the post treatment period. This regression model is:

$$
Y_{i d t}=\alpha_{D D-C A} P K P A c t_{d t}+X i \beta_{D D-C A}+T_{d t} \rho+\text { Disabled }_{d}+\gamma_{t}+\epsilon_{i d t}
$$

The only differenece between this and Equation 2 is that instead of a dummy variable for treatment (PKPAct $\left.t_{s}\right)$ I compute the interaction $C A_{s}$, an indicator variable for living in California, with indicator variables for each year, $\gamma_{t}$, in my sample (1994 to 2007). This set of treatment variables captures the difference between individuals with disabilities in California and individuals with disabilities outside of California for each year.

\section{Difference-in-Differences: California Sample (DD-CA)}

The regression model for the DD-CA is: 


$$
Y_{i d t}=\alpha_{D D-C A} P K P A c t_{d t}+X_{i} \beta_{D D-C A}+T_{d t} \rho+\text { Disabled }_{d}+\gamma_{t}+\epsilon_{i d t}
$$

The additional $d$ subscript added here refers to disability status, and Disabledd is an indicator variable for having a disability. PKPActdt is an indicator variable equal to one for being an individual with a disability in 2001 or later. The time fixed effects, $\gamma_{t}$, capture any shocks or trends in the Californian economy that affected individuals with and without disabilities equally. These shocks are only controlled for in DD-Disabled in so far as they are captured by the state-by-year controls Controlsst, which only capture a portion of the possible shocks. This is a strength of the DD-CA over the DD-Disabled, under the assumption that the individuals without disabilities would have experienced the same shocks. However, the DD-Disabled has the advantage of capturing national-level trends or shocks faced by individuals with disabilities, relative to individuals without disabilities. The time trends $\left(T_{d t}\right)$ are now disability status-specific linear time trends instead of state-specific linear time trends. I present $95 \%$ confidence intervals estimated from heteroskedastic-robust standard errors.

The coefficient of interest is $\alpha_{D D-C A}$ which captures the effect of the PKP Act for individuals with disabilities relative to individuals without disabilities. "Relative" is key here, as the PKP Act could elicit substitutions between individuals with and without disabilities. For this reason, the effects estimated by this DD could be larger in magnitude that the effects estimated by the DDDisabled. I also estimate the effects over time in a similar fashion to Equation 3.

\section{Difference-in-Differences-in-Differences (DDD)}

The DDD methodology augments both DDs by combining the controls groups of individuals without disabilities (from DD-CA) and the other states (from DD-Disabled):

$$
Y_{i d s t}=\alpha_{D D D} P K P A c t d s t+X_{i} \beta_{D D D}+\left(\text { Controls } \times \text { Disabled }_{d}\right) \lambda_{D D D}+T_{d s t} \rho+\theta_{d s}+\delta_{s t}+\gamma_{d t}+\epsilon_{i d s t}
$$


Again with a similar specification mirroring Equation 3 to estimate the effects by year. PKPActdst is an indicator variable equal to one for being 2001 or later, living in California, and having a disability. The DDD includes disabled-by-state $\left(\theta_{d s}\right)$ state-by-year $\left(\delta_{s t}\right)$, and disabled-by-year $\left(\gamma_{d t}\right)$ fixed effects. Controls $s_{s t}$ includes the four sets of control variables described above for Equation 1, except the state unemployment rate ${ }^{24}$. I interact Controls $s_{s t}$ with a disability indicator variable so that effects can differ between individuals with and without disabilities. For the minor changes in disability discrimination laws and the hiring credits for individuals with disabilities, this interaction is required as these policies are specific to individuals with disabilities. The extensions to unemployment insurance are available to both individuals with and without disabilities, and would be subsumed by the state by year fixed effects if included as-is. I include the extra weeks available interacted with the Disabled $_{d}$ indicator variable to allow the effects of extra weeks of unemployment insurance to differ between individuals with and without disabilities. I present both Conley-Taber confidence intervals and confidence intervals from clustering on state.

The DDD has the added appeal of controlling for additional factors that could be correlated with the PKP Act, and thus could bias estimation of the effect of the PKP Act. The DD-Disabled only controls for national trends or shocks affecting individuals with disabilities regardless of state of residence. The DD-CA controls for trends or shocks affecting Californians, regardless of their disability status. The DDD goes beyond both DDs by controlling for three additional factors:

1. Average labor market outcomes for individuals with and without disabilities in each state (using state-by-disabled fixed effects);

\footnotetext{
${ }^{24}$ The state unemployment rate is subsumed by the state by time fixed effects. However, the interaction between this and disability status would not be. It is possible, as shown by Schur (2003) (p. 613), that individuals with disabilities are less sensitive to state unemployment rates. My results are unchanged when this interacted control is included (see Online Appendix 4).
} 
2. National trends or shocks in labor market outcomes for individuals with disabilities, relative to individuals without disabilities (using disabled-by-year fixed effects); and,

3. Shocks or trends in state labor markets that affect individuals with and without disabilities equally (using state-by-year fixed effects).

However, there still remains the possibility that the DDD estimate of the PKP Act could be biased by any shocks or trends that affected Californians with disabilities, relative to Californians without disabilities, and relative to the gap between those with and without disabilities in other states. This could be, for example, changes in state laws or programs that I did not locate and are thus not controlled by Controls $d s t \times$ Disabled $_{d}$.

Another possible source of bias is differential trends in the gap between Californians with and without disabilities, relative to the same gap in other states. This is a possibility. Houtenville and Burkhauser (2004) and Bound and Waidmann (2002) attribute the negative employment trend for individuals with disabilities, relative to individuals without disabilities, that started in the 1980s to changes in SSDI and SSI programs that made them more accessible. California is one of the states that supplements the federal SSI program with extra funds, and does so the most generously (Neumark and Powers, 1998). This could lead employment to decline faster for some Californians with disabilities relative to those with disabilities in other states. For this reason I include disabledby-state-specific linear time trends $\left(T_{d s t}\right)$ in one set of regressions.

\section{Results}

Table 4 presents estimates of $\alpha_{D D-D i s}\left(\right.$ Columns (1) and (2)), $\alpha_{D D-C A}($ Columns (3) and (4)), and $\alpha_{D D D}($ Columns (5) and (6)), all for employment (Panel (a)), unemployment (Panel (b)), and labor force participation (Panel (c)). Even columns include group-specific linear time trends ${ }^{25}$.

\footnotetext{
${ }^{25}$ State-specific linear time trends in Column (2), disability status-specific linear time trends in Column (4), and state-by-disability status-specific time trends in Column (6).
} 
Confidence intervals using state-clustered standard errors (Columns (1), (2), (5) and (6)) or heteroscedasticity-robust standard errors (Columns (3) and (4)) are shown in brackets under the coefficient estimates. For Columns (1), (2), (5), and (6), Conley-Taber confidence intervals are presented below in parentheses.

\section{[[Table 4 near here]]}

Starting with employment, the preferred estimate is from the DDD with state-by-disability status-specific linear time trends (Column (6)): a 3.8 percentage point increase in the probability of being employed. All the estimates with linear time trends are similar (0.037 to 0.039) and are all statistically significant at at least the 0.05 level using either confidence interval. However, the estimates without group-specific linear time trends differ significantly from each other and from the estimates with trends. So while the positive and statistically significant employment effect estimates with time trends are robust to the particular DD or DDD identification used, they are not robust to the inclusion or exclusion of time trends.

Figure 3 presents three sub-figures: the estimated effects over time for the DD-Disabled (Equation 3) in sub-figure (a), for the DD-CA in sub-figure (b), and for the DDD in sub-figure (c), all for employment. Following Reber (2005), I present the annual treatment effect estimates relative to the estimated effect the year before treatment (2000), which is set to be zero. Each subfigure includes $95 \%$ confidence intervals calculated using either state-clustered standard errors (for the DD-Disabled and the DDD) ${ }^{26}$ or using heteroscedasticity-robust standard errors (for the DD-CA). Imposed over the figures are regression lines fit to the pre-treatment period data before 2001 and extended into the post-treatment period. These show an estimate of the pre-trend in

\footnotetext{
${ }^{26}$ I do not include Conley-Taber confidence intervals in sub-figures (a) and (c) because they are particularly large and they obscure the ability to see the trends discussed in this section. These confidence intervals are very wide and do not show any year being statistically significantly different from 2000. These are available upon request.
} 
employment for individuals in disabilities in California relative to the comparison groups(s) and what would have happened in the post-treatment period had treatment not occurred and this same trend persisted.

\section{[[Figure 3 near here]]}

All sub-figures show an increase in the employment rate right after passage of the PKP Act in 2001. For the DD-Disabled, the probability of employment increases by 4.0 percentage points from 2000 to 2001, and then by 1.7 percentage points from 2001 to 2002. From then on the estimates generally decline. This is similar, but weaker, for the DD-CA (a 1.5 percentage point increase in 2001, 0.8 in 2002) and the DDD $(3.1,1.1)$. However, the confidence intervals for the DD-CA are very large, so no annual estimates in the post-treatment period are statistically significantly different from the estimate in 2000.

All sub-figures show negative pre-trends in employment for Californians with disabilities relative to the control group(s) (the downward sloping dashed lines). The slope of these pre-trend lines indicates the average decrease per year in the pre-period. For the DD-Disabled this is 0.0016 (0.16 percentage points). This is larger for the DD-CA (0.0145) and for the DDD (0.0057). Given that the average probability of employment in the pre-period for Californians with disabilities in my sample is $24.5 \%$, some of these pre-trends are sizable 27 .

These negative trends suggest that, relative to the control group(s), the employment of Californians with disabilities declined over time. These negative trends explain why the estimates change so much when group-specific linear time trends are included. Where the trends are strongest (DD-CA), the estimates change the most (from a 4.0 percentage point decrease in

\footnotetext{
${ }^{27}$ The negative trends in the pre-period for the estimates in Figure 3 may suggest that the PKP Act was enacted as a reaction to this declining employment. However, this is highly unlikely to be the case given the history and motivation behind the PKP Act, which I discuss in Online Appendix 1.
} 
probability of employment without trends, to a 3.7 percentage point increase, with trends). Where the trends are relatively weaker (DD-Disabled), the estimate doesn't change by quite as much (a 2.1 percentage point increase changes to a 3.9 percentage point increase). Because of these large pre-treatment trends, I see the estimates with time trends as much more accurate.

Comparing the estimates in the post-treatment period to the pre-treatment period trend line is a useful way to see what the effects were net of this existing trend, under the assumption that this trend would have continued had the PKP Act not occurred. For the DD-Disabled, the increase in employment occurs primarily from 2001 to 2003, with the effect dissipating from 2004 to 2007 to become either insignificant relative to the trend in some years or significant but about half as large as the peak effect in 2002 (a 7.0 percentage point difference between the estimate and the trend). For the DD-CA, the pre-trend line seems to match the lower confidence interval, so that only a few years are statistically significant $(2002,2005,2007)$, with the magnitude of the effect being roughly the same since 2002. For the DDD, the effect seems relatively constant from 2002 to 2007, other than the insignificant estimate in 2006. In general these comparisons to the pre-trend suggest that it took a year for effects to occur, and they likely persisted, at least in part, up to six years later. This contrasts somewhat with Jolls and Prescott (2004) who find that the ADA only had an effect the first few years after its adoption.

Table 4, Panel (b) presents the estimated effects on unemployment. Mirroring the estimates for employment, the unemployment estimates are similar when group-specific linear time trends are included, ranging from a 1.4 (the preferred estimate) to a 1.8 percentage point decrease in the probability of being unemployed, all statistically significant at the 0.05 level using both confidence intervals. Again, the estimates without group-specific linear time trends show much smaller effects that are only statistically significant for the DD-CA. 
Table 4, Panel (c) presents the effects on labor force participation, which are similar to the employment effects in statistical significance but are smaller in magnitude. The preferred estimate (Column (6)) is a 2.4 percentage point increase in the probability of being in the labor force, statistically significant at at least the 0.05 level under both confidence intervals. Again, all estimates that include group-specific linear time trends are similar in magnitude, although the estimate of $\alpha D D$-Dis is not statistically significant under Conley-Taber confidence intervals.

These results suggest that more of the employment increase comes from net movements from labor force non-participation to employment than from net movements from unemployment to employment. While the unemployed have more attachment to the labor force, and thus it is more likely that increased employment would occur for them, there are far more individuals with disabilities who are not in the labor force (71.1\% in California in the pre-period) than unemployed (4.5\%). This may explain why the estimated impacts for labor force participation are larger in magnitude than the estimated unemployment impacts. But the preferred estimate of the unemployment decrease (1.4 percentage points, Column (6)) is large relative to the proportion of Californians with disabilities in the pre-period who are unemployed (4.5\%). This is a large increase in the ability of those with disabilities with stronger labor force attachment to secure (or hold onto) employment.

\section{Conclusion}

In 2001, the Prudence Kay Poppink Act (PKP Act) significantly broadened who was considered disabled under California's disability discrimination law. While there were five changes resulting from the PKP Act, the most important was California explicitly requiring only that individuals have an impairment that "limits" a major life activity, rather than "substantially limits" as in the federal ADA. This change reduced the legal burden for plaintiffs to prove that 
they were disabled and led to broader coverage of discrimination protections to individuals with less severe disabilities.

I quantify the impacts of the PKP Act on individuals with disabilities using a two difference-in-difference (DD) regression analysis frameworks: comparing individuals with disabilities in California before and after the PKP Act to individuals with disabilities in other states over the same time period (DD-Disabled), and comparing Californians with disabilities to those without disabilities over the same time period (DD-CA). I then augment this to a difference-indifference-in-differences (DDD) by incorporating both control groups: individuals with disabilities in other states (from DD-Disabled) and individuals without disabilities (from DD-CA).

The results generally show that the PKP Act led to an increase in employment for individuals with disabilities. My preferred estimate comes from the DDD with state-by-disability status-specific linear time trends, which shows an average increase in employment of 3.8 percentage points in the seven years after the PKP Act (2001 to 2007). This effect is large relative to the employment rate of Californians with disabilities in the 1994-2000 period before the PKP Act $(24.5 \%)$. This effect peaks in the year after the PKP Act took effect persists over the entire sample period.

While my estimated employment effects are robust to the methodology used (DD-CA, DDDisabled, DDD), they are sensitive to if group-specific time trends are included. I show and argue that there are negative existing trends in the employment of Californians with disabilities relative to individuals with disabilities in other states, but especially relative to individuals without disabilities, and that these trends lead to negative bias in the estimate of the effect of the PKP Act if they are not included. Thus, while the estimates are not robust to the exclusion of group-specific linear time trends, the results without these trends are very suspect anyways. 
Given the positive estimated employment effects of the PKP Act, California's broader disability discrimination protections after the PKP Act could be seen as a model for how states could expand their discrimination protections to reduce employment barriers for individuals with disabilities by going beyond the relatively limited protections offered by the ADA. Since the PKP Act shares similarities with the ADA Amendments Act of 2008 (ADAAA), these results also suggest that the ADAAA likely had positive effects, but this should be explored in future work. However the PKP Act is even broader than the ADAAA, so there is scope for the federal government to make disability discrimination protections even broader than the ADA after the ADAAA.

My finding that this broadening disability discrimination protections had positive effects may also apply more broadly to employment discrimination laws for other protected groups (e.g., race, gender, age). The employment impacts of disability discrimination laws are likely to be more negative relative to laws for other protected groups due to the increased hiring costs from the reasonable accommodation requirement. However, since I find positive effects anyways, this may suggest that discrimination protections for other groups could also boost employment. 


\section{References}

Abadie, Alberto, Alexis Diamond, and Jens Hainmueller. 2010. "Synthetic Control Methods for Comparative Case Studies: Estimating the Effect of California's Tobacco Control Program." Journal of the American Statistical Association, 105(490): 493-505

Acemoglu, Daron, and Joshua D. Angrist. 2001. "Consequences of Employment Protection? The Case of the Americans with Disabilities Act." Journal of Political Economy, 109(5): 915957.

Adams, Scott J. 2004. "Age discrimination legislation and the employment of older workers." Labour Economics, 11: 219-241.

Beegle, Kathleen, and Wendy A. Stock. 2003. "The Labor Market Effects of Disability Discrimination Laws.” Journal of Human Resources, 38: 806-859.

Bell, David, and Axel Heitmueller. 2009. "The Disability Discrimination Act in the UK: Helping or hindering employment among the disabled?" Journal of Health Economics, 28(2): 465-480.

Bertrand, Marianne, Esther Duflo, and Sendhil Mullainathan. 2004. "How Much Should We Trust Differences-In-Differences Estimates?" The Quarterly Journal of Economics, 119(1): 249-275.

Bloch, Farrell. 1994. Antidiscrimination Law and Minority Employment: Recruitment Practices and Regulatory Constraints. Chicago: University of Chicago Press.

Bound, John. 1991. "Self-reported versus objective measures of health in retirement models." Journal of Human Resources, 26, 106-38.

Bound, John, and Richard V. Burkhauser. 1999. "Economic Analysis of Transfer Programs Targeted on People With Disabilities," in Handbook of Labor Economics, Vol. 3C eds. Orley Ashenfelter and David Card, Amsterdam: Elsevier Science, pp. 3417-3528.

Bound, John, and Timothy Waidmann. 2002. "Accounting for Recent Declines in Employment Rates among Working-Aged Men and Women with Disabilities." Journal of Human Resources, 37(2): 231-250.

Burgdorf, Robert L. 1997. "Substantially Limited: Protection from Disability Discrimination: the Special Treatment Model and Misconstructions of the Definition of Disability." Villanova Law Review, 42(2): 409-586.

Burkhauser, Richard V., Andrew J. Houtenville, and David C. Wittenburg. 2001. "A User Guide to Current Statistics on the Employment of People with Disabilities." Paper presented at the Conference on "The Persistence of Low Employment Rates of People With DisabilitiesCause and Policy Implications", October 18-10, 2001, Washington, DC, Draft 10/03/01. 
Burkhauser, Richard V., Mary C. Daly, Andrew J. Houtenville, and Nigar Nargis. 2002. "Self-Reported Work-Limitation Data: What They Can and Cannot Tell Us." Demography, 39: 541-555.

Byron, Deborah A. 2012. "Disability Discrimination and the Obligation to Provide Reasonable Accommodation: the Interactive Process." Retrieved May 1, 2015, from http://www.mondaq.com/unitedstates/x/160950/Discrimination+Disability+Sexual+Harassment/ Disability + Discrimination + And + The + Obligation + To+Provide + Reasonable + Accommodation $+\mathrm{T}$ he+Interactive +Process.

Colker, Ruth. 1999. "The Americans with Disabilities Act: A Windfall for Defendants." Harvard Civil Rights Civil Liberties Law Review, 34: 99-162.

Conley, Timothy G., and Christopher R. Taber. 2011. "Inference with Difference in Differences with a Small Number of Policy Changes." Review of Economics and Statistics, 93(1): 113-125.

Daly, Mary C., and Fred Furlong. 2002. "Profile of a Recession - The U.S. and California." San Francisco, CA: Federal Reserve Board of San Francisco Economic Letter \#2002-04.

DeLeire, Thomas. 2000. "The Wage and Employment Effects of the Americans with Disabilities Act.” Journal of Human Resources, 35(4): 693-715.

Donohue, J, and J Heckman. 1991. "Continuous Versus Episodic Change: The Impact of Civil Rights Policy on the Economic Status of Blacks." Journal of Economic Literature, 29(4): 16031643.

Donohue, John J. 2007. “Antidiscrimination Law." In Handbook of Law and Economics. , ed. A. M. Polinsky and Steven Shavell, 1387-1472. Elsevier.

Farber, Henry S., and Robert G. Valletta. 2015. "Do Extended Unemployment Benefits Lengthen Unemployment Spells? Evidence from Recent Cycles in the U.S. Labor Market." Journal of Human Resources, 50(4): 873-909.

Flood, Sarah, Miriam King, Steven Ruggles, and J. Robert Warren. 2015. Integrated Public Use Microdata Series, Current Population Survey: Version 4.0 [Machine-readable database]. Minneapolis: University of Minnesota

Harned, Karen R., and Katelynn K. McBride. 2010. "The Amendments to the Americans with Disabilities Act: Bad for Business, Boon for the Disabled?" Engage: The Journal of the Federalist Society Practice Groups, 11(3): 99-103.

Hill, Matthew J., Nicole Maestas, and Kathleen J. Mullen. 2014. "Employer Accommodation and Labor Supply of Disabled Workers.” RAND Labor and Population Working Paper WR1047. 
Hotchkiss, Julie L. 2004. "A Closer Look at the Employment Impact of the Americans with Disabilities Act." Journal of Human Resources, 39(4): 887-911.

Houtenville, Andrew J., and Richard V. Burkhauser. 2004. "Did the Employment of People with Disabilities Decline in the 1990s, and was the ADA Responsible: A Republican and Robustness Check of Acemoglu and Angrist (2001).” Ithica, NY: Research and Rehabilitation Training Center for Economic Research on Employment Policy for Person with Disabilities, August 2004.

Jolls, Christine, and J. J. Prescott. 2004. "Disaggregating Employment Protection: The Case of Disability Discrimination." Cambridge, MA: National Bureau of Economic Research Working Paper Series, No. 10740.

Kapteyn, Arie, James P. Smith, and Arthur van Soest. 2011. "Work disability, work, and justification bias in Europe and the United States," in Explorations in the Economics of Aging, pp. 269-312. Chicago: University of Chicago Press.

Kerkhofs, Marcel, and Maarten Lindeboom. 1995. "Subjective health measures and state dependent reporting errors." Health Economics, 4(3): 221-235.

Kliesen, Kevin L. 2003. "The 2001 Recession: How Was It Different and What Developments May Have Caused It?" St. Louis, MO: Federal Reserve Bank of St. Louis Review September/October 2003 Vol. 85, No. 5, pp. 23-38.

Kreider, Brent. 1999. "Latent work disability and reporting bias." Journal of Human Resources, 34(4): 734-769.

Kreider, Brent, and John V. Pepper. 2007. "Disability and Employment: Reevaluating the Evidence in Light of Reporting Errors." Journal of the American Statistical Association, 102(478): 432-441.

Kruse, Douglas, and Lisa Schur. 2003. "Employment of People with Disabilities Following the ADA." Industrial Relations, 42(1): 31-64.

Lahey, Joanna N. 2008. "State Age Protection Laws and the Age Discrimination in Employment Act." Journal of Law and Economics, 51(3): 433-460.

Long, Alex B. 2004. "State Anti-Discrimination Law as a Model for Amending the Americans with Disabilities Act." University of Pittsburgh Law Review, 65: 597-653.

Long, Alex B. 2008. "Introducing the New and Improved Americans with Disabilities Act: Assessing the ADA Amendments Act of 2008." Northwestern University Law Review, 103: 217229. 
Martell, Michael E. 2013. "Do ENDAs End Discrimination for Behaviorally Gay Men?" Journal of Labor Research, 34(2): 147-169.

Meer, Jonathan, and Jeremy West. 2016. "Effects of the minimum wage on employment dynamics.” Journal of Human Resources, 51(2); 500-522.

Mora, Ricardo, and Iliana Reggio. 2013. "Treatment Effect Identification Using Alternative Parallel Assumptions." Universidad Carlos III de Madrid Working Papers, 12-33(March 2013).

Neumark, David. 2009. "The Age Discrimination in Employment Act and the Challenge of Population Aging." Research on Aging, 31(1): 41-68.

Neumark, David, and Diego Grijalva. 2013. "The Employment Effects of State Hiring Credits During and After the Great Recession." Cambridge, MA: National Bureau of Economic Research Working Paper Series, No. 18928.

Neumark, David, and Elizabeth Powers. 1998. "The effect of means-tested income support for the elderly on pre-retirement saving: evidence from the SSI program in the U.S." Journal of Public Economics, 68(2): 181-206.

Neumark, David, and Joanne Song. 2013. "Do stronger age discrimination laws make Social Security reforms more effective?" Journal of Public Economics, 108: 1-16.

Neumark, David, and Patrick Button. 2014. "Did Age Discrimination Protections Help Older Workers Weather the Great Recession?" Journal of Policy Analysis and Management, 33(4): 566-601.

Neumark, David, and Wendy A. Stock. 1999. "Age Discrimination Laws and Labor Market Efficiency.” Journal of Political Economy, 107(5): 1081.

Neumark, David, and Wendy A. Stock. 2006. "The Labor Market Effects of Sex and Race Discrimination Laws." Economic Inquiry, 44(3): 385-419.

Neumark, David, Joanne Song, and Patrick Button. 2016. "Does Protecting Older Workers from Discrimination Make it Harder to Get Hired? Evidence from Disability Discrimination Laws." Forthcoming in Research on Aging.

Oguzoglu, Umut. 2012. "Is there a better measure of self-assessed disability?" Applied Economics Letters, 19, 1335-1338.

Reber, Sarah J. 2005. "Court-ordered desegregation - Successes and failures integrating American schools since Brown versus Board of Education.” Journal of Human Resources, 40(3): 559-590.

Schur, Lisa A. 2003. "Barriers or opportunities? The causes of contingent and part-time work among people with disabilities." Industrial Relations, 42(4): 589-622. 
Taylor, Barry C. 2009. "Court Interpretations of Major Life Activities Under the ADA: What Will Change After the ADA Amendments Act?" Chicago, IL: DBTAC Great Lakes ADA

Center, April 2009.

Thompkins, Allison V. 20015. "Did the ADA Evolve into Our Ramp to Full Employment? An Analysis of 18 Years of the Americans with Disabilities Act." Journal of Contemporary Management, 13-32

Figure 1: Timeline of Major Legal Events and my Sample Period

Sutton Trilogy: Sutton v. United Airlines, Murphy v. UPS, Albertson's

v. Kirkingburg (June 1999)

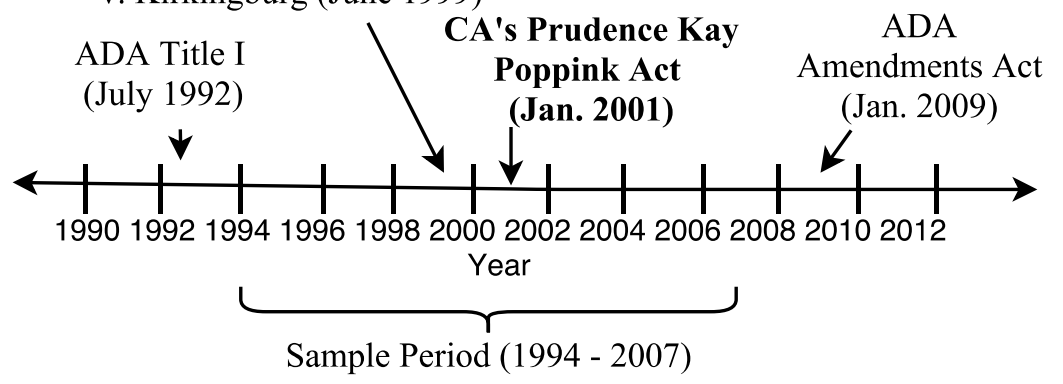


Figure 2: Proportion of Sample with Work-Limiting Disabilities

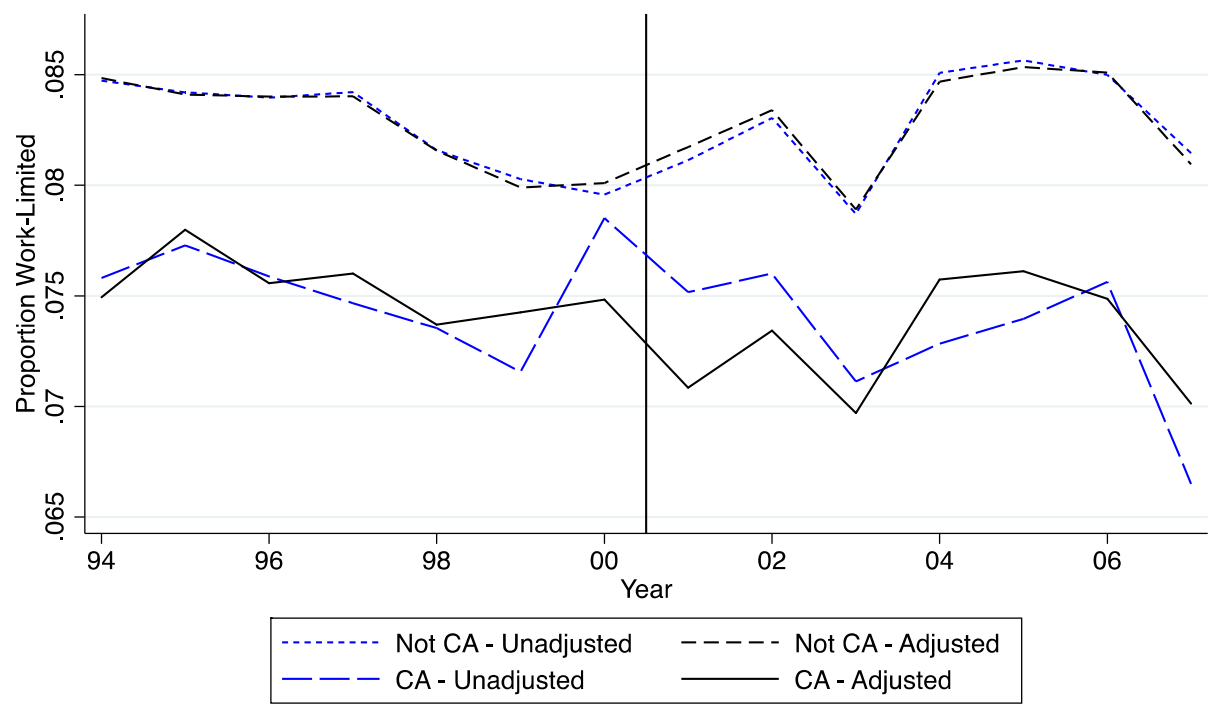

Notes: These estimates are generated from CPS ASEC data for individuals from age 25 to 61 . Unadjusted estimates are raw average by year while adjusted estimate are the average predicted probabilities by year from the logit regression in Equation 1. Population weights are used to create population-representative series. 
Figure 3: Estimated Employment Effects by Year

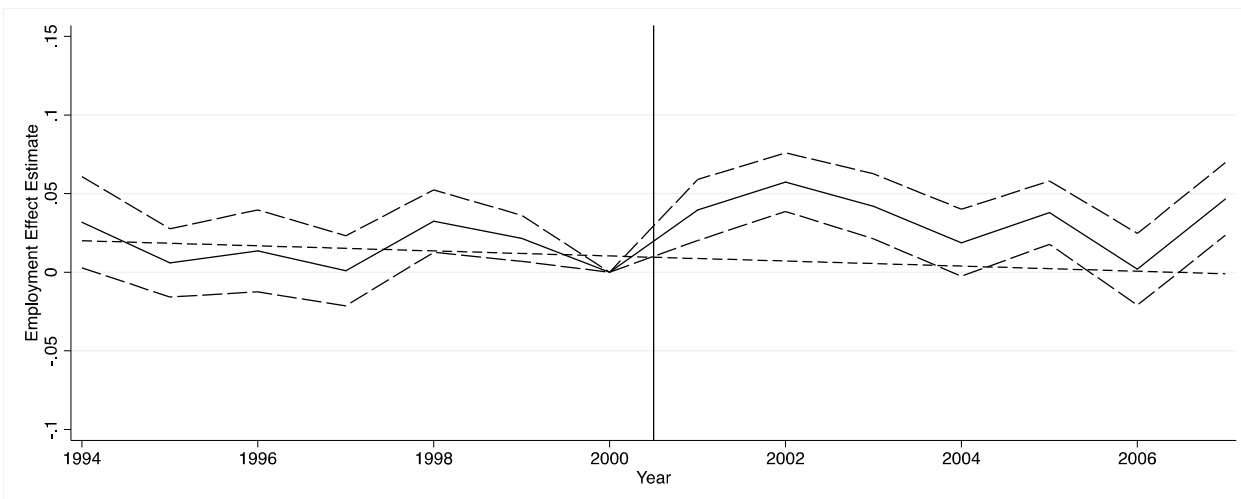

(a) CA - Not CA, Disabled Sample Only (DD-Disabled)

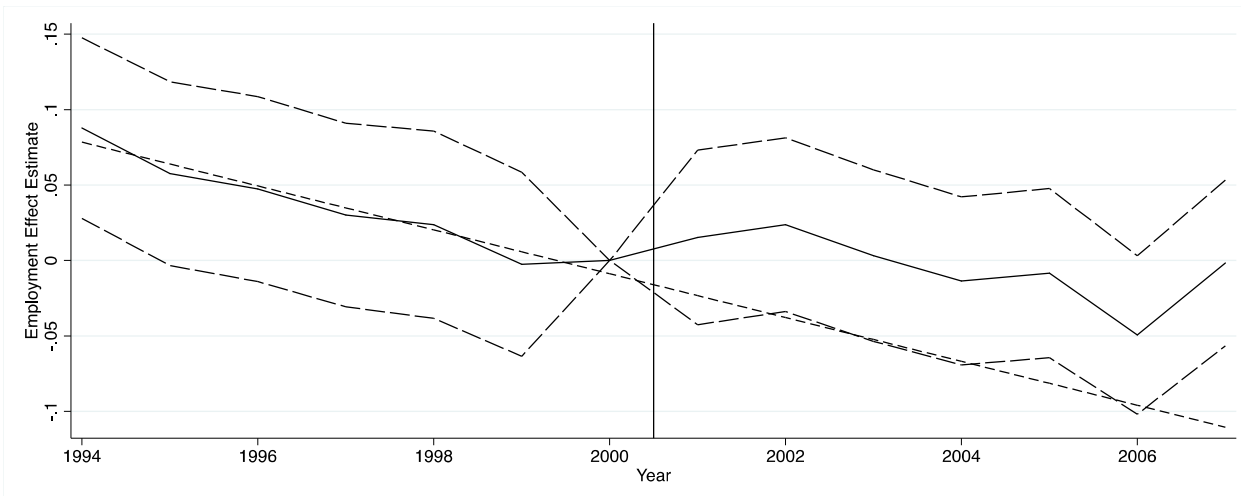

(b) Disabled - Non-Disabled, California Sample Only (DD-CA)

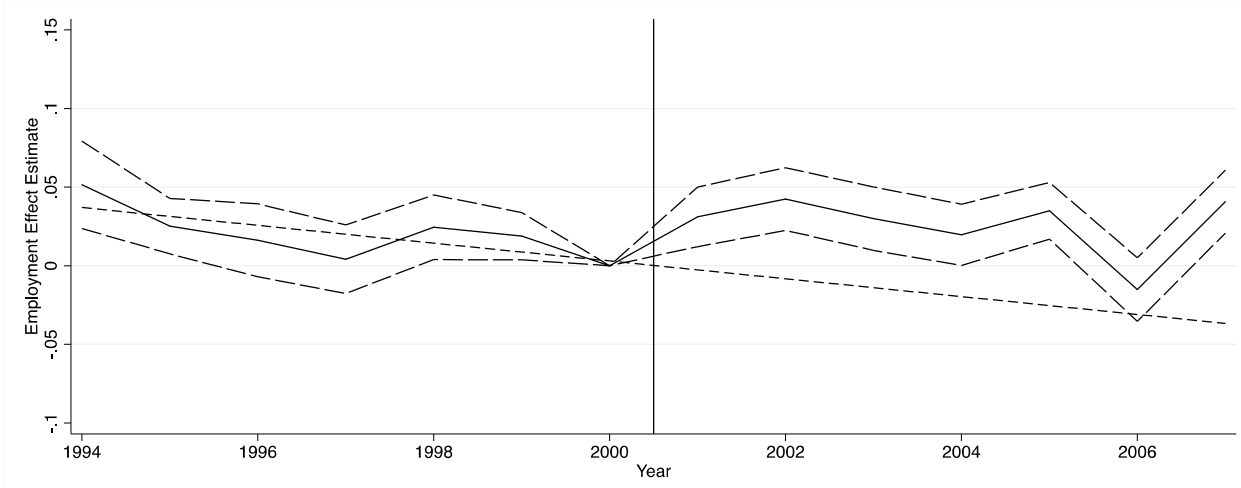

(c) Difference-in-Difference by Year (DDD)

Notes: Estimates come from Equation 3 (for sub-figure (a)) and similar regressions for the DD-CA (sub-figure (b)) and the DDD (sub-figure (c)). Estimates are relative to the year before the PKP Act took effect (2000), which is set to zero. 95\% confidence intervals are reported based on state-clustered standard errors (a, c) or heteroskedasticity-robust standard errors (b). Conley-Taber confidence intervals are possible for (a) and (c) but are not reported (available upon request). The downward sloping dashed line is a best-fit line fit over the pre-treatment period and extended into the post-treatment period. These show the average linear pre-treatment trend and how the employment gap would have evolved had the PKP Act not been passed and this same trend were to have continued. 
Table 1: Summary Statistics - Demographics

2001-2007

Non-Disabled Disabled Non-Disabled Disabled

CA

Not CA

Age

Female (\%)

White (\%)

Black/Negro (\%)

Asian or Hawaiian/Pacific Islander $(\%)$

American Indian/Aleut/Eskimo (\%)

Other Single Race (\%)

Two or More Races (\%)

Hispanic (\%)

Never Married/Single (\%)

Married (\%)

Separated, Divorced, or Widowed

(\%)

Less than High School\%

High School or GED (\%)

Some College (\%)

Post-Secondary Degree (\%)

N
$\mathrm{CA}$

Not CA

CA

Not CA

$\mathrm{CA}$

Not CA

$\mathrm{CA}$

Not CA

CA

Not CA

$\mathrm{CA}$

Not CA

CA

Not CA

CA

Not CA

$\mathrm{CA}$

Not CA

$\mathrm{CA}$

Not CA

$\mathrm{CA}$

Not CA

CA

Not CA

$\mathrm{CA}$

Not CA

$\mathrm{CA}$

Not CA

$\mathrm{CA}$

Not CA

$\mathrm{CA}$

Not CA

$\mathrm{CA}$

Not CA
(1)

(2)

7.5

8.3

40.2

40.8

49.9

51.3

80.5

84.2

6.2

12.1

11.9

2.7

0.8

0.7

0.6

0.2

0

0

28.5

8.6

20.9

16.8

63.9

67.3

15.3

15.9

17.7

11

23.8

34.4

20.2

18.4

38.3

36.2

41,879

389,169

45.3

45.9

50.7

77.9

77.1

20.1

1.2

1.9

1.4

0.4

0.3

0

0

8.3

24

47.3

46.9

28.7

29.4

26.3

31.1

37.5

21.8

15.8
(3) 7.3

8.3

(4)

46.6

41.3

47.2

42

51.5

50.8

50.2

51.9

51

75.7

77.9

75.9

11.4

82.4

12.3

5.9

19.7

12

8.1

13.9

1.7

23.5

23.7

29.4

22.6

15.6

3,119

34,066

616,748

14.5
15.7

15.7

17.6

10

21.9

31.4

18.7

17.7

41.7

41

56,572

4,079

51,363

Notes: Presented here are means of summary statistics for those 25 to 61 in the CPS ASEC from 1994 to 2007.

$\begin{array}{ccccc}\text { Not CA } & 389,169 & 34,066 & 616,748 & 51,363\end{array}$ Means are weighted using population weights. The CPS revised its race and Hispanic origin questions in 2003 by 
removing the "Other" option and replacing it with options for two or more combinations. For simplicity, this table presents some aggregated categories: "Hawaiian/Pacific Islander only" is combined with "Asian only", and all two or more race options are combined. "Married, spouse present" is combined with "Married, spouse absent", and "Separated", "Divorced", and "Widowed" are combined. Each possible year of incomplete education are aggregated up to "Less than High School", "Some College", and all levels of post-secondary degree are presented aggregated as "Post-Secondary Degree". Regressions include indicator variables for each possible survey response rather than these aggregated groups.

Table 2: Summary Statistics - Labor Market Outcomes

\begin{tabular}{|c|c|c|c|c|c|}
\hline & & 1994-2 & & $2001-2$ & \\
\hline & & $\begin{array}{c}\text { Non-Disabled } \\
\text { (1) }\end{array}$ & $\begin{array}{l}\text { Disabled } \\
\text { (2) }\end{array}$ & $\begin{array}{l}\text { Non-Disabled } \\
\text { (3) }\end{array}$ & $\begin{array}{c}\text { Disabled } \\
\text { (4) }\end{array}$ \\
\hline Employed (\%) & $\mathrm{CA}$ & 79.1 & 24.5 & 79.4 & 20.4 \\
\hline & Not CA & 83.2 & 25.2 & 82.6 & 20.3 \\
\hline Unemployed (\%) & $\mathrm{CA}$ & 4.8 & 4.5 & 4.2 & 3.6 \\
\hline & Not CA & 3.4 & 3.3 & 3.6 & 3.2 \\
\hline In Labor Force $(\%)$ & $\mathrm{CA}$ & 83.9 & 28.9 & 83.5 & 24 \\
\hline & Not CA & 86.6 & 28.5 & 86.2 & 23.5 \\
\hline Weeks Worked & $\mathrm{CA}$ & 40.6 & 13.3 & 40.6 & 11.2 \\
\hline & Not CA & 42.6 & 13.2 & 42.3 & 10.9 \\
\hline Received SSI/DI (\%) & $\mathrm{CA}$ & 0.6 & 35 & 0.6 & 37.4 \\
\hline & Not CA & 0.6 & 29.7 & 0.5 & 29.3 \\
\hline State Unemployment Rate (\%) & $\mathrm{CA}$ & 6.6 & & 5.8 & \\
\hline & Not CA & 4.8 & & 5.1 & \\
\hline Extra Available Weeks of UI & $\mathrm{CA}$ & 0 & & 4.4 & \\
\hline & Not CA & 0 & & 4.4 & \\
\hline $\mathrm{N}$ & CA & 41,879 & 3,119 & 56,572 & 4,079 \\
\hline & Not CA & 389,169 & 34,066 & 616,748 & 51,363 \\
\hline
\end{tabular}

Notes: See the notes to Table 1. The extra weeks of unemployment insurance come from Farber and Valletta (2015). 
Table 3: Estimated Change in the Probability of Reporting Being Disabled (Work-Limited) in California after the Prudence Kay Poppink Act

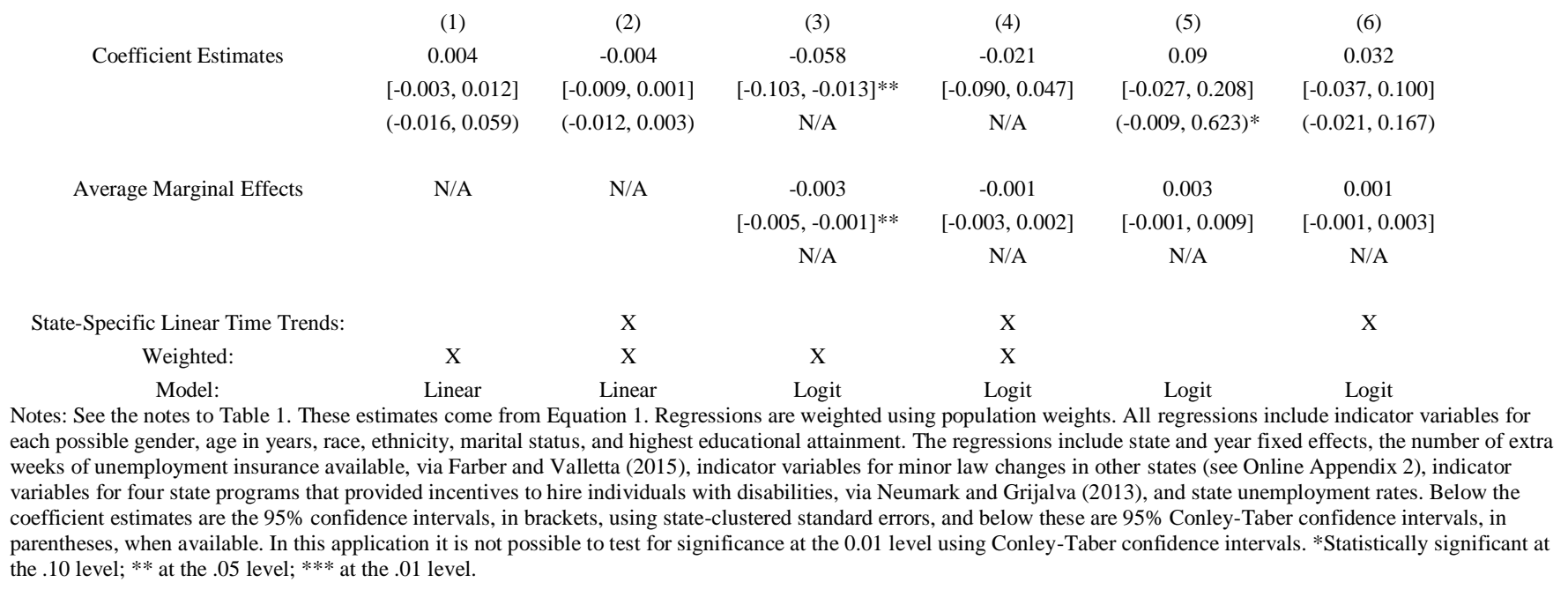


Table 4: Effects on Employment Status

DD-Disabled

(1)

(a) Employed

0.021

$[0.009,0.034]^{* * *}$

$(-0.038,0.116)$

(b) Unemployed

$-0.003$

$[-0.008,0.001]$

$(-0.017,0.019)$

$[-0.021,-0.011]^{* *}$

$(-0.026,-0.006)^{* *}$

(c) Labor Force Participation

0.018

$[0.006,0.030]^{* * *}$

$(-0.041,0.101)$
0.023

$[0.006,0.040]^{* *}$

$(-0.006,0.051)$
Identification:

DD-CA

(3)

(4)

$-0.040$

$[-0.050,-0.028]^{* * *}$

$\mathrm{N} / \mathrm{A}$

0.037

$[0.025,0.049]^{* * *}$

N/A

$-0.018$

$[-0.008,-0.001]^{* *}$

N/A

$[-0.025,-0.011]^{* * *}$

N/A

0.019

$-0.044$

$[0.015,0.024]^{* * *}$
N/A
0.006

$[-0.003,0.015]$

$(-0.033,0.076)$
DDD

(6)

0.038

$[0.020,0.056]^{* * *}$

$(0.017,0.062)^{* * *}$

$-0.014$

$[-0.019,-0.009] * * *$

$(-0.021,-0.006)^{* *}$

0.024

$[0.006,0.042]$ ***

$(0.000,0.045)^{* *}$

Linear Time Trends:

$\mathrm{X}$

$\mathrm{X}$

Notes: See the notes to Table 1 and 3. Columns (1) and (2) include state and year fixed effects, the number of extra weeks of unemployment insurance available, via Farber and Valletta (2015), indicator variables for minor law changes in other states (see Online Appendix 3), indicator variables for four state programs that provided incentives to hire individuals with disabilities, via Neumark and Grijalva (2013), and state unemployment rates. Columns (5) and (6) include state-by-year, disabled-by-year, and state-bydisabled fixed effects, and the above listed state-level policy and economic controls each interacted with a disabled indicator variable. Column (2) includes state-specific

linear time trends, Column (4) includes a disabled-specific linear time trend, and Column (6) includes state-by-disabled-specific linear time trends. All regressions include the same demographic controls as in Equation 1 and Table 3. Columns (3) and (4) present, in brackets, 95\% confidence intervals based on heteroskedasticity-robust standard errors. All other columns present confidence intervals based on state-clustered standard errors (in brackets) and following Conley and Taber (2011) (in parentheses). All regressions are weighted using population weights. 